\title{
Responses of Economic Activity to Global Oil Market Shocks: A Comparative Analysis of Major Net Oil-Producing and -Consuming Countries
}

\author{
M-ALI SOTOUDEH \\ Griffith University and University of Sistan and Baluchestan \\ ANDREW C. WORTHINGTON \\ Griffith University
}

\begin{abstract}
We argue four channels drive oil price shocks namely the oil supply, aggregate demand, oilspecific demand and real exchange rates during 1986M5-2013M1. Our findings are that oil price shocks driven by oil supply positively affect net oil-consumer countries faster than net oil-producer countries. Oil price shocks driven by aggregate demand are largely country specific. Oil Shocks driven by other demands influence net oil-producers faster than net oil-consumers negatively, and persistently mostly among net oil-producers. Other shocks have large negative effects on the industrial production of all countries, with responses appearing very quickly and persisting for at least a year.
\end{abstract}

Keywords: structural oil price shocks, structural vector auto regression (SVAR), parametric nonlinear test, impulse-response functions, net oil-consuming and -producing countries

\footnotetext{
${ }^{*}$ JEL classifications: F40, O14, Q43

Correspondence: M-Ali Sotoudeh, Griffith University, Email: ma.sotoudeh@griffithuni.edu.au
} 


\section{Introduction}

In general, the literature on the macroeconomic effects of oil price shocks yields mixed findings, mostly because of the diversity of estimation methods used, the means used to identify shocks, variation in sampling, and the inconsistent specification of variables. But for the most part, it is generally believed that depending on the structure of the economies in question, the macroeconomics of oil-importing countries will suffer (benefit) from oil price rises (falls), while those of oil-exporting countries will benefit (suffer) from oil price rises (falls).

However, such a broad distinction does not accurately reflect the full potential influences of oil price changes on an economy where there is a discrepancy between oil production and oil exporting and oil consumption and oil importing. For instance, just 11 of the world's 15 leading oil-producing countries are also leading oil exporters, suggesting that the volume of oil production is not strictly consistent with being an oil exporter or importer. Similarly, while the US is the world's largest oilimporting country and a leading consumer, it is also a leading oil producer. Thus, there may well be differences in the reactions of these and other economies to oil price shocks if they are a large oil producer and a small oil consumer or a large oil consumer and a small oil producer or a large oil importer or a large oil exporter.

Theoretically, a fall in the oil price should benefit oil-importing countries and harm oil-exporting countries. For the former, the reduction of the oil price is akin to a tax cut as it increases consumer disposable income. Central banks will then expand the money supply, and the subsequently lower interest rates and inflation should invoke greater economic activity and higher share prices, which finally lead to increased economic growth. Conversely, we expect higher oil prices to be associated with subdued economic growth and even economic downturns in oil-importing countries.

In this paper, we focus on net oil production and consumption instead of oil exporting and importing as a share of GDP. We also aim to correct the existing imbalance in findings given the usual focus on oil importers (here net consumers) and on oil exporters (here net producers), mainly because reliable and consistent data are usually more difficult to obtain for the latter. To compare the responses of economic activity of net oil-consuming and -producing countries to origin-driven oil price shocks, we first follow Kilian (2009) to measure structural oil market shocks. These shocks include the oil supply, aggregate demand, and precautionary (oil-specific) demand shocks. We also consider other shocks in the analysis to compare the effects of non-oil shocks on industrial production. 
Then, utilizing a parametric nonlinear approach, we test for the existence of nonlinear causation among the target variables. Finally, we employ the structural vector auto regressive (SVAR) approach to measure the responses of industrial production to the measured oil market shocks already calculated. The remainder of the paper is structured as follows. Section II reviews the existing literature on the subject. Section III discusses the data and methods, and Section IV provides the estimation results. Section V details some brief concluding remarks.

\section{Transmission of Oil Price Shocks to Economic Activity}

The effects of oil price changes on economic activity have been documented widely in the literature (see, for example, Hamilton, 1983, 1996, 2003; Gisser and Goodwin, 1986; Mork, 1989; Hooker, 1996, Burbidge and Harrison, 1984; Mork et al., 1994; Jimenez-Rodriguez and Sanchez, 2005, 2009 and Kilian, 2008). Among several methods of measuring economic activity, two proxies are most common, namely, GDP and industrial production. In seminal work, Mork (1989) found that oil price reductions do not exert a statistically significant impact on US GDP, and subsequently found evidence of an asymmetric inverse relationship between oil price changes and aggregate economic activity for Norway and G7 countries (Mork, 1994).

Many subsequent studies confirm Mork’s $(1989,1994)$ early findings. For instance, Lardic and Mignon (2008) provided evidence for asymmetric cointegration between oil prices and GDP. Likewise, He et al. (2010) used a supply-demand model and Kilian's economic index as a proxy for global economic activity and showed that real future prices of crude oil are cointegrated with both economic activity and the trade-weighted US dollar. Using a single-equation error-correction model (ECM), He et al. (2010) suggested that the adjustment implied by a permanent change in Kilian's index is a relatively drawn out process.

Although GDP is one of the best available measures of overall economic activity, it cannot fully satisfy the requirements of reflecting the reactions of economic activity to oil price shocks. For instance, the reaction of industrial production to oil market shocks in an industrial country could be stronger than the reaction in GDP, which in turn may differ in less-industrialized economies. Furthermore, if oil prices increase, GDP will decline because of the income effect. This is because GDP represents domestic value-added and national accounting should deduct the cost of imported oil. At the same time, the labour supply and industrial production will increase in response to the oil price shock (Lee and Ni, 2002). However, the input cost effect will decrease both GDP and industrial production. 
When industrial production serves as a proxy for cash flows, the results also fit with the theory of rational valuation. For example, Jones and Kaul (1996) examined stock market efficiency using an arbitrage pricing theory model, whereby changes in expected future cash flows and the future returns on the underlying assets are reflected in stock prices. Jones and Kaul (1996) showed that cash flows affect stock returns positively. Park and Ratti (2008) found that when real US stock returns influence real stock returns in European markets, oil price shocks exert a statistically significant impact on real stock returns across all European countries at the same time or with a lag of one month.

In general, there is little existing evidence on the relation between industrial production and oil price shocks at the industry level (for example, see Bohi, 1989; Lee and Ni, 2002; Kilian and Park, 2009; Herrera, 2011). Most of these studies focus on the US, the exception being Bohi (1989) (also including Germany, Japan, and the UK). However, there are some differences, with Bohi (1989) and Lee and $\mathrm{Ni}$ (2002) analysing the impact of oil price shocks on output in manufacturing, whereas Kilian and Park (2007) and Herrera (2007) investigated the effects on industry-level stock returns and inventory sales, respectively.

Jimenez-Rodriguez (2008) likewise addressed the diverse responses of industrial production to oil price shocks using key manufacturing industries across six OECD countries. The results suggested that the pattern of responses of industrial output to an oil price shock varied across the four European Monetary Union countries included (France, Germany, Italy, and Spain), but were broadly similar between the UK and the US. Later, Jimenez-Rodriguez (2011) argued that differences in macroeconomic structure were the main reason for the diversity in responses of national economies to oil price shocks, with cross-country differences partly explained by differences in the transmission mechanism.

Lastly, Lee and Ni (2002) used demand-supply analysis to explain the macroeconomic effects of oil price shocks. They showed that on the supply side, oil-intensive industries would reduce production, but that on the demand side, the industrial production responses were less clear. One reason could be that the production of less-oil-intensive industries declines if the demands of moreoil-intensive industries also decrease. However, an increase in the demand of more-oil-intensive industries, may also increase the demand and supply of less-oil-intensive industries. 


\section{Data and Methods}

\section{(i) Data}

Our sample data consist of global oil prices, industrial production, and real exchange rates for seven net oil-consuming countries and three net oil-producing countries. Our sample selection criterion is the share of net oil production (consumption) in GDP, using which we identify the US, Brazil, Denmark, Italy, Germany, the Netherlands and Sweden as net oil consumers and Canada, Mexico and Norway as net oil producers. Table 1 summarises the oil production and consumption shares of GDP in the sample countries.

\section{$<$ TABLE 1 ABOUT HERE $>$}

We use monthly data covering the period 1986M5-2013M1. The data for industrial production (IP) and the nominal exchange rate (ER) are from the Organisation for Economic Co-operation and Development (OECD). Using each country's consumer price index and specifying the US dollar as the reference currency, we then calculate the real exchange rate for each country. We also use the monthly oil prices of West Texas Intermediate (WTI) crude oil, a very widely used oil pricing benchmark given its strong correlation with Brent and Dubai, the other major crude oil prices (Wang et al. 2013). We collect WTI price data from the World Bank website. Then using the monthly US CPI index collected from the OECD website, we calculate inflation-adjusted real oil prices. Finally, we index all data to their 2010 monthly averages.

\section{(ii) Methods}

In this section, we explain the econometric methods used in our analysis. These include a SVAR model to measure shocks to oil prices as well as shocks in real exchange rates, a parametric nonlinear approach to test nonlinear causation, and impulse-response analysis to measure the responses of industrial production to structural shocks.

\section{Structural shocks}

We measure crude oil market shocks using the two-block structural shock approach presented by Kilian (2009). To start with, consider the following standard SVAR model:

$$
\boldsymbol{A} \boldsymbol{Y}_{\boldsymbol{t}}=\alpha+\sum_{i=1}^{j} \boldsymbol{B}_{\boldsymbol{i}} \boldsymbol{Y}_{\boldsymbol{t}-\boldsymbol{i}}+\varepsilon_{t}
$$

where $\boldsymbol{Y}=(\triangle O S, \triangle R A, \Delta O P, \Delta E R)^{\prime}$ are the log-differences in the global oil supply (OS), the Kilian index of global real economic activity $(R A)$, the global oil price $(O P)$, and the country-specific real 
exchange rate $(E R)$ variables, respectively. We assume the exogenous error terms $\left(\varepsilon_{t}\right)$ are serially and mutually structural innovations. The lag length $j$ is selected to be equivalent to 24 . $\boldsymbol{A}$ is a fullrank matrix such that $\boldsymbol{A}^{\mathbf{- 1}}$ is a recursive structure defining the reduced form of $e_{t}=\boldsymbol{A}^{-\mathbf{1}} \varepsilon_{t}$. The decomposition is as follows:

$$
e \equiv\left(\begin{array}{c}
e_{t}^{\Delta O S} \\
e_{t}^{\Delta R A} \\
e_{t}^{\Delta O P} \\
e_{t}^{\Delta E R}
\end{array}\right)=\left[\begin{array}{cccc}
a_{11} & 0 & 0 & 0 \\
a_{21} & a_{22} & 0 & 0 \\
a_{31} & a_{32} & a_{33} & 0 \\
a_{41} & a_{42} & a_{43} & a_{44}
\end{array}\right]\left(\begin{array}{c}
\varepsilon_{t}^{\text {Oil supply shock }} \\
\varepsilon_{t}^{\text {Aggregate demand shock }} \\
\varepsilon_{t}^{\text {Other oil-specific shock }} \\
\varepsilon_{t}^{\text {Other exchange-specific shock }}
\end{array}\right)
$$

Referring to Equation 2, the structural innovations define oil market shocks as unpredictable innovations to global crude oil production. Drawing on Kilian’s (2009) definitions, shocks to the global demand for industrial commodities (aggregate demand shocks) are then those innovations to global real economic activity not explained by crude oil supply shocks. Oil-specific demand shocks, interpreted as precautionary demand shocks, are the innovations to the real price of oil unexplained by oil supply and aggregate demand shocks. Finally, the other exchange-specific shocks are innovations in the real exchange rate not explained by the oil supply, aggregate demand and other oil-specific shocks.

There are some restrictive assumptions underpinning the above decomposition. First, oil supply innovations do not respond to shocks in aggregate demand, other oil-specific and other exchangespecific shocks in the short term. This allows us to consider the oil supply shocks exogenously. We justify this by the assumption that oil producer countries largely control global oil production, which induces either no response or less of a response to short-term changes in the oil market.

Second, global economic activity responds to global oil price shocks immediately, while oilspecific and country-specific exchange rate shocks have no effect on global economic activity in the short term. As discussed in Kilian (2009), oil-specific shocks may influence global economic activity after a month. Moreover, if there is any influence of shocks in country-specific exchange rates, it may take more than a month to alter global economic activity.

Finally, as Kilian (2009) and Kilian and Park (2009) discuss, other oil-specific shocks are interpreted as precautionary demand shocks induced by the expected shortfalls in oil supply. These shocks do not respond to the exchange rate innovations in a country within a month as they mainly result from uncertainty in the future global oil supply. Further, there are other shocks to countryspecific exchange rates caused by a large number of other economic and non-economic factors. Thus, we separate any other factors that affect the real exchange rate, and hence industrial production, from those influencing the crude oil market and industrial production. 


\section{Parametric nonlinear test}

The first step in examining the effects of structural shocks on industrial production is exploring the existence of any nonlinear causation of these shocks over industrial production through applying a parametric nonlinear test. The test is similar to the linear Granger causality test. However, it follows the Mackey-Glass (1977) process with special parameters estimated by ordinary least squares. We follow the modified Mackey-Glass approach by Kyrtsou and Labys (2006), which is suitable for our estimation. To start, suppose we have the following two country-specific models:

$$
\begin{aligned}
& D L S_{i t}=\alpha_{11} \frac{D L \hat{\zeta}_{i t-\tau_{1}}}{1+D L \hat{\zeta}_{i t-\tau_{1}}^{C_{1}}}-\delta_{11} D L \hat{\zeta}_{i t-1}+\alpha_{12} \frac{D L I P_{t-\tau_{2}}}{1+D L I P_{t-\tau_{2}}^{c_{2}}}-\delta_{12} D L I P_{t-1}+z_{t} \quad i=1,2,3,4 \\
& D L I P_{t}=\alpha_{21} \frac{D L \hat{\zeta}_{i t-\tau_{1}}}{1+D L \hat{S}_{i t-\tau_{1}}^{C_{1}}}-\delta_{21} D L \hat{S}_{i t-1}+\alpha_{22} \frac{D L I P_{t-\tau_{2}}}{1+D L I P_{t-\tau_{2}}^{\mathrm{C}_{2}}}-\delta_{22} D L I P_{t-1}+u_{t} \quad i=1,2,3,4
\end{aligned}
$$

where $D L I P_{t}$ and $D L \varsigma_{i t}$ are the log-differences in industrial production and the oil market shocks estimated by Equations 1 and 2, respectively. $D$ is the first-difference operator; $L$ denotes the logarithm; $\hat{\varsigma}$ indicates oil price structural shocks; $i$ refers to each of the four types of oil price structural shocks we identify in this analysis, $\tau=\max \left(\tau_{1}, \tau_{2}\right)$ is the calculated integer delays, $\mathrm{c}$ is the constant and $t=\tau, \tau+1, \ldots, N$. The parameters $\alpha$ and $\delta$, denote the linear and nonlinear effects of the cause variable, respectively. Finally, the two error terms $z_{t}$ and $u_{t}$ are assumed to be $\mathrm{N}(0,1)$. The first step in running this nonlinear approach is to select the integer delays $\tau_{i}$ and constants $c_{i}$ prior to any other estimation. For this, we employ the Schwarz information criterion (SIC) and Akaike information criterion (AIC).

Based on this model, if $\alpha_{11}$ is significantly different from zero, the oil price structural shock is determined to nonlinearly Granger-cause industrial production under the null hypothesis. To test whether $\alpha_{11}$ equals zero, we need to estimate each equation once with no constraint and again with the constraint of a zero value for $\alpha_{11}$ (and also $\alpha_{22}$ for the reverse test). Assuming $\hat{\vartheta}$ and $\hat{\mu}$ are the residuals of the two models, respectively, we calculate the following Fisher-distributed test statistic:

$$
S_{F}=\frac{\left(S_{c}-S_{u}\right) / n_{c}}{S_{u} /\left(T-n_{u}-1\right)} \sim F\left(n_{c}, T-n_{u}-1\right)
$$

where $S_{u}=\sum_{t=1}^{T} \hat{\vartheta}^{2}, S_{c}=\sum_{t=1}^{T} \hat{\mu}^{2}$, and $n_{u}=4$ given the four parameters in our (un)constrained (Mackey-Glass) models and $n_{c}=1$ as only one parameter needs to be zero when estimating the constrained model. Depending on the value of this calculated F-statistic, we determine whether $\alpha_{11}$ 
(and $\alpha_{22}$ ) are different from zero and conclude whether our estimated structural shocks nonlinearly Granger-cause industrial production.

\section{Linear regression model}

To consider the linear responses of industrial production to the estimated crude oil shocks, we follow Kilian's (2009) linear approach to measuring impulse responses. We decompose the country-specific forecast error variances of each shock to determine the contribution of each shock to the variations in industrial production. To calculate the impulse responses, consider the following country-specific equation:

$$
\operatorname{DLIP}_{t}=\delta_{j}+\sum_{i=0}^{24} \varphi_{j i} \hat{\hat{S}}_{j t-i}+\omega_{j t} \quad j=1,2,3,4
$$

where $D L I P$ and $\hat{\varsigma}$ are the log-differences in industrial production and the shocks estimated using Equations 1 and 2, respectively, $\delta$ is the constant term and $\omega$ is the error term. The purpose of Equation 6 is to identify the model coefficients $(\varphi)$, which indicate the industrial production responses to each of the shock impulses over a 24-month horizon (Kilian, 2009). Consequently, the number of lags is determined by the maximum horizon of the impulse-response function. Importantly, the error terms are then potentially serially correlated, implying biased estimation of the standard errors. To address this, we employ bootstrapping methods to extract the standard errors.

\section{Results}

We first consider the presence of any nonlinear effects in the structural shocks on countryspecific industrial production. Table 2 presents the results applying the modified nonlinear parametric Mackey-Glass model. The table include the lag order and the power of each shock affecting industrial production separately along with the relevant test statistic with F-distribution.

\section{$<$ TABLE 2 ABOUT HERE $>$}

As shown, the power of the cause variable (e.g. shocks) is unitary in all cases. This reduces the likelihood of nonlinear causal effects of such shocks on industrial production. Further, oil shocks generally influence industrial production within four months in almost all cases. The oil supply shocks affect industrial production of net oil-consuming countries between 1-3 months. However, this period appears to be longer in most net oil-producing countries: 7 months in Canada, 6 months in Mexico but only one month in Norway. The lag length for the aggregate demand shock effects do 
not differ much between the two panels, with the lags varying between 1-4 months in net oilconsuming countries and 2-3 months in net oil-producing countries. The lag lengths for the effects of the other oil-specific shocks also vary significantly, particularly across net oil-consuming countries, with lag lengths of one month in Brazil, Sweden, and the US, 3 months in the Netherlands, 4 months in Denmark and Germany, and 8 months in Italy. In contrast, the lag lengths in net-oil producing countries range from just one month in both Norway and Mexico, and 4 months in Canada. Finally, other shocks in real exchange rates also appear to affect industrial production, with a general lag of 2-3 months with the exception of Brazil, Norway, and Mexico where the lag is only 1 month.

We then perform the modified nonlinear parametric Mackey-Glass tests for each sample country based on the predetermined parameters. Recall that this test allows us to detect the nonlinear causality running from our estimated shocks to industrial production without distinguishing between the signs of their changes. The findings indicate that there is no evidence confirming nonlinear causation, except in the case of oil supply shocks in Mexico, aggregate demand shocks in Norway, and oil-specific shocks in Italy.

The nonlinearity tests show that there is little evidence of nonlinearity across our sample of net oil-consuming and producing countries. This finding suggests that a linear specification may well capture the linkage between crude oil shocks and industrial production movements. The absence of nonlinearity also reduces the likelihood of model misspecification in this analysis and increases the reliability of our results.

\section{(i) Country-Specific Responses to Global Oil Supply Shocks}

Using the structural VAR model presented in Equation 6, we now consider the country-specific responses of economic activity to global oil price shocks. Fig. 1 depicts the responses of the individual net oil-consuming and -producing countries. As shown, the unexpected increase in global oil production exerts significant positive effects on economic activity in both net oil-consuming and -producing countries. This is intuitive as the increased oil supply reduces oil prices and consequently industry costs. Thus, we expect an expansion in industrial production. The only exceptions among the net oil-consuming countries are the responses in Brazil and the Netherlands, which are statistically significantly negative and zero, respectively.

\section{$<$ FIGURE 1 ABOUT HERE $>$}

Fig. 1 also shows that economic activity responses to oil supply shocks in net oil-consuming countries appear a few months later than in net oil-producing countries. Apart from the US, which 
responds almost immediately, and Brazil, which responds negatively after 2 months, other net oilconsuming countries exhibit significant positive responses within 2-12 months. Conversely, whereas Canada and Mexico as net oil-producing countries respond almost immediately, Norway only begins to respond in the second half of the second year. Altogether, we find that there is no significant difference between our two sample panels in the magnitude and direction of responses to global oil supply shocks. Furthermore, industrial production across the various net oil-consuming countries responds to the oil supply shocks very similarly, but this is not the case in the net oilproducing countries, as illustrated in Table 3.

\section{$<$ TABLE 3 ABOUT HERE $>$}

\section{(ii) Country-Specific Responses to Global Oil Demand Shocks}

Fig. 2 depicts the effects of the unanticipated shocks in global aggregate demand on countryspecific industrial production. As shown, the responses of economic activity to shocks in aggregate demand are statistically significant in most countries, although the pattern does appear to vary by country, and across a wider range in net oil-producing countries than net oil-consuming countries. Moreover, while global aggregate demand has a significant positive influence on industrial production in Brazil, Germany, Italy and Sweden, it exerts zero and significantly negative effects in the Netherlands and Denmark, respectively. However, the US uniquely responds positively during the first year and negatively during the second year. Among the net oil-producing countries, Norway and Mexico exhibit very late significant negative responses to global aggregate demand shocks, whereas the industrial production responses in Canada tend to follow the lead set by the US.

\section{$<$ FIGURE 2 ABOUT HERE $>$}

Overall, it would appear that the structural differences existing between our sample economies, previously identified by Jimenez-Rodriguez (2011) as the main source of the diverse countryspecific responses of industrial production to global oil price shocks, is mostly the result of unanticipated shocks to global aggregate demand. Such differences in macroeconomic structures shed light on the possible impact of net oil consumption and production. Thus, we cannot extend our results illustrated in Fig. 2 to all net oil-consuming and producing countries. Furthermore, it is intuitive that shocks in the global economic activity index, as presented by Kilian (2009), induce the increases in crude oil prices (He et al., 2011).

An increase in oil prices will then result in higher industry costs (Jung and Park, 2011). This is a sensible result for oil-intensive industries in both consumption and production (such as transportation equipment). As time elapses, these negative effects may gradually offset the positive 
effects of increasing demand in the markets, which require production expansion (Kilian and Park, 2009). Thus, two opposing influences are responsible for the diverse responses to global demand shocks. This could also be the reason for the highly country-specific responses of industrial production to aggregate demand shocks. Table 4 confirms this country-specific reaction. Fig. 2 also shows that the impact of increasing oil prices due to shocks in global aggregate demand in net oilproducing countries are less substantial than in net oil-consuming countries. This finding contrasts with Sotoudeh and Worthington (2014), which proved the existence of a cointegrating relationship between oil price changes and industrial production, but only for net oil-consuming countries.

\section{$<$ TABLE 4 ABOUT HERE $>$}

\section{(iii) Country-Specific Responses to Other Global Oil Price Shocks}

Fig. 3 depicts the cumulative responses of country-specific industrial production to other oilspecific shocks. Importantly, these shocks are only associated with global oil price shocks not explained by shocks in oil demand and supply. The impulse responses indicate that the influences of other oil-specific shocks on industrial production are substantially negative across net oil-producing countries and most net oil-consuming countries. Furthermore, with the exception of Brazil and Denmark, positive reactions follow the initial negative responses during the first year in both net oil-producing and -consuming countries. The patterns appear very similar across both panels of countries.

\section{$<$ FIGURE 3 ABOUT HERE $>$}

Kilian (2009) and Alquist and Kilian (2010) define other oil-specific shocks as shocks to precautionary demand induced by the expectation of a shortfall in oil supply. Kilian (2009) demonstrates that unanticipated oil-specific demand increases will have an immediate, large and persistent positive effect on real oil prices. Thus, we can expect negative responses in industrial production to oil market shortfalls in the long term. However, in the short term, oil-specific demand shocks induce a temporary increase in global economic activity (Kilian, 2009). Overall, despite being classed as net oil consumers or producers in our analysis, industrial production in all countries responds to oil-specific shocks very similarly, as shown in Table 5.

\section{$<$ TABLE 5 ABOUT HERE $>$}

\section{(iv) Country-Specific Responses to Other Shocks to the Real Exchange Rate}

Fig. 4 illustrates the country-specific responses of industrial production to unanticipated domestic currency depreciation from shocks other than shocks in the supply, demand, and 
precautionary demand for oil. Given that the exchange rate represents the domestic value of one unit of foreign currency, the sources of these shocks may include shocks in government expenditures, imports, exports, inflation, the money supply, or indeed any other factor affecting the real exchange rate. Fig. 4 provides evidence indicating that these shocks exert statistically significant and large influences on the real exchange rates of country-specific industrial production across both net oil-consuming and -producing countries.

One important implication of this finding is that any change in industrial production where an oil supply, demand, or precautionary demand shock appears does not necessarily demonstrate the reaction of industrial production to such shocks. While oil shocks may affect country-specific industrial production, either directly or indirectly, other shocks to real exchange rates may affect industrial production dissimilarly. As shown in the figure, the industrial production responses to non-oil shocks in real exchange rates are mostly negative during the first year in both panels. Thus, this reaction can mitigate the initial positive effects of other oil shocks on industrial production presented earlier.

\section{$<$ FIGURE 4 ABOUT HERE $>$}

Fig 4 also shows that the duration and magnitude of the negative effects in net oil-producing countries seem to be more than that in net oil-consuming countries. In net oil-producing countries, industrial production responds negatively to other shocks in real exchange rates in all three countries, especially in Norway, but also in Canada and Mexico. However, in net oil-consuming countries, four of the seven net oil-consuming countries exhibit initial negative responses to other shocks in real exchange rates. In Germany, Italy, and the Netherlands, the reduction in industrial production is either not significant or less than in other net oil consumers because of the arguably beneficial effects of the European Union’s common currency (Jamil et al., 2012). In Brazil and Sweden, we observe significant large decreases in industrial production. In the US, the responses increase up to 600 percent by the end of the second year.

There are two opposing flows, which specify the current direction of responses to non-oil shocks in real exchange rates, in both panels. The domestic currency depreciation increases the price of intermediate goods including crude oil. The subsequent increase in the cost of production, particularly in net oil-consuming countries, reduces industrial production. On the other hand, the currency depreciation will also increase net exports and aggregate demand. This promotes an increase in industrial production. Consequently, the combination of these flows forms the direction of movement of industrial production responding to shocks in real exchange rates. These results 
indicate that the long-term effects of non-oil shocks in real exchange rates are mostly positive in both panels, with generally stronger negative effects across net oil-producing countries. Furthermore, industrial production in net oil-consuming countries reacts to these shocks similarly, while such reactions are heterogeneous across net oil-producing countries, as shown in Table 6.

\section{$<$ TABLE 6 ABOUT HERE $>$}

\section{(v) Forecast Error Variance Decomposition}

To quantify the contribution of oil price shocks to variations in industrial production, we employ variance decomposition analysis. Figures 5 and 6 depicts the variance decomposition results of the forecasting errors for industrial production in net oil-consuming and -producing countries at forecast lengths of 1, 6, 12 and 24 months, respectively.

\section{$<$ FIGURE 5 ABOUT HERE $>$}

We first consider the difference in the absolute contribution of each shock to changes in industrial production for the two samples of countries. First, in net oil-consuming countries, the contribution of oil supply shocks in industrial production gradually decreases (Brazil, Denmark, US), increases (Germany, Sweden) or fluctuates (Italy, Netherlands) whereas the same trend is only decreasing across net oil-producing countries. The average contribution of oil supply shocks in industrial production across net oil-consuming countries is 23 per cent with the exceptions of Denmark and the US (with a much higher contribution) and Germany (with a lower contribution). However, these seem to be significantly higher in net oil-producing countries where they explain 45 per cent of the changes in industrial production on average.

Second, the role of aggregate demand shocks in explaining the industrial production variations appears to fluctuate over time in net oil-consuming countries and to decrease in net oil-producing countries. In net oil-consuming countries other than Sweden, the contribution of aggregate demand shocks during the first month is less than all other periods (4.8 per cent on average). For Sweden, however, such contribution to the variations in industrial production during the first month is 39 percent. There is no significant difference between net oil-consuming and -producing countries in terms of the maximum and minimum variation in the role of aggregate demand shocks in industrial production changes over time.

Third, the contribution of other oil price shocks on the variation in industrial production differs significantly across the sample countries. Among net oil-consuming countries, it declines in Brazil, Germany, the Netherlands, and the US, but not in Denmark, Italy, and Sweden. Similarly, the 
contribution of other oil price shocks in the industrial production variation of net oil-producing countries also fluctuates over the time. However, these shocks explain less of the variation in industrial production in net oil producers than in net oil consumers, particularly during the first six months. Finally, the contribution of other shocks in real exchange rates seems to be increasing during the first year in most of the sample countries. In Brazil, Germany, the Netherlands, and Sweden among the net oil-consuming panel and in Canada and Mexico among the net oil-producing panel, other shocks in real exchange rates have almost no power in the first month in explaining the variation in industrial production. It then increases within the entire sample of net oil-consuming and producing countries over the next 6 months and only then varies.

\section{$<$ FIGURE 6 ABOUT HERE $>$}

A second interpretation of the results presented in Figs. 5 and 6 is the difference in the comparative contribution of each shock between the two sample panels. During the first month, oil supply shocks (in Denmark and the US) and other oil price shocks (in the remaining net oilconsuming countries) explain major variations in industrial production, whereas among net oilproducing countries, only oil supply shocks explain more than 60 percent of the changes in industrial production. As time elapses, the contribution of each estimated shock in net oilconsuming countries becomes equal with the exception of Germany and the US. In Germany, other oil price shocks always perform the greatest role in explaining the variations of industrial production. In the US, industrial production variations are better explained by other shocks in real exchange rates during the period. However, in net oil-producing countries, oil supply shocks are still the most significant source of the variation in industrial production during the first year, and then gradually replaced with other shocks to real exchange rates. Finally, where aggregate demand shocks across net oil-consuming countries make the least contribution to industrial production variations in average, other oil price shocks perform a similar role in net oil-producing countries.

\section{Conclusion}

Oil as a strategic commodity affects national economic activity, not only in terms of demand, but also when it injects income through the supply side. A significant reduction in oil prices will benefit oil importers and harm oil exporters. For oil-importing countries, lower oil prices are similar to a tax cut, which increases consumer disposable income. This allows central banks to expand money aggregates. Due to the larger cash flows, lower interest rates as well as lower inflation cause higher economic activity and higher share prices. Surging industrial production finally leads to higher economic growth. In contrast, higher oil prices are commonly held responsible for downturns and recession in oil-importing countries. 
Given the possible adverse effects of an oil price shock on both oil-importing and oil-exporting economies, we conducted further comparative research on the country-specific reactions of economies to oil price shocks of different origin. Thus, using a two-block structural shock model, we first measured oil supply shocks, aggregate demand shocks, oil-specific demand shocks and other shocks appearing in the exchange rate. Oil supply shocks are unpredictable innovations to global crude oil production. Shocks to the global demand for industrial commodities (aggregate demand shocks) are those innovations to global real economic activity not explained by crude oil supply shocks. Oil-specific demand shocks, interpreted as precautionary demand shocks, are innovations to the real price of oil unexplained by oil supply shocks or aggregate demand shocks. Finally, other exchange-specific shocks are innovations in real exchange rates not explained by oil supply shocks, aggregate demand shocks and other oil-specific shocks.

Our comprehensive investigation included testing for the existence of both linear and nonlinear influences of oil price shocks on economic activity. Consequently, we initially explored the nonlinear causation of oil price shocks to industrial production, commonly used as proxy for economic activity. The parametric nonlinear tests show that there is little evidence of nonlinearity across sample net oil-consuming and -producing countries. This finding suggests that a linear specification may well capture the linkage between crude oil shocks and industrial production movements in the context of this study. The absence of such nonlinearity reduces the likelihood of model misspecification in this paper and increases the reliability of the results.

In the next step, we considered the linear responses of economic activity to the estimated shocks in crude oil market. The results of our linear country-specific impulse response estimations are as follows. First, the oil supply shocks affect economic activity in net oil-consuming countries after 13 months. This period, however, seems to be longer in net oil-producing countries, and ranges between 1-7 months. Aggregate demand shocks influence economic activity after 1-4 months in net oil-consuming countries and 2-3 months in net oil-producing countries. The lag lengths for the effects of other oil-specific shocks vary significantly across the two panels of countries. The lag length generally varies from 1-8 months within net oil-consuming countries and 1-4 months across net oil-producing countries. Other shocks in real exchange rates seem to affect economic activity persistently, which takes 2-3 months within all countries on average.

Second, unexpected increases in global oil production exert significant positive effects on economic activity in both net oil-consuming and -producing countries. The estimations indicate that there is no significant difference in the responses of the two groups of countries to oil price shocks driven by oil production. Nevertheless, net oil-consuming countries generally respond to the oil- 
production-driven shocks slower than net oil-producing countries. Third, the oil price shocks driven by aggregate demand shocks affect most net oil-consuming and -producing countries. However, the results vary significantly. Such diversity seems greater among net oil-producing countries than net oil-consuming countries. This finding reveals that the structural differences in national economies, given as the major reason for the diverse reactions of countries to the oil price shocks, are significant only when aggregate demand shocks drive the oil price shocks.

Fourth, oil-specific demand shocks associated with global oil price shocks but unexplained by shocks in oil demand and supply negatively affect the economic activity of net oil-producing countries. Such effects are evident in most of the sample net oil-consuming countries. The pattern and variation in industrial production responses appear very similar across all sample countries. Furthermore, we found that in addition to initial temporary increase in industrial production due to an oil-specific demand shock, as found in other studies, these shocks affect industrial production negatively in the long term.

Fifth, as we define the real exchange rate as the domestic value of one unit of foreign currency, the sources of these shocks in real exchange rate may include shocks in government expenditures, imports, exports, inflation, the money supply, or indeed any other factor affecting real exchange rates. We found that shocks in real exchange rate exert a statistically significant and large influence on country-specific industrial production across all countries. The industrial production responses to non-oil shocks in real exchange rate are mostly negative during the first year. This reaction can mitigate the initial positive effects of oil price shocks on industrial production calculated in previous sections. In addition, the duration and magnitude of negative effects in net oil-producing countries seem to be higher than that in net oil-consuming countries.

Finally, while the contribution of oil supply shocks in the variation of industrial production of net oil-producing countries generally decreases over a two-year horizon, it varies across net oilconsuming countries. This contribution is equivalent on average to 23 percent in net oil-consuming countries and 45 percent in net oil-producing countries. The contribution of oil price shocks driven by aggregate demand shocks in industrial production variation during a two-year horizon is the same as the contribution of oil supply shocks. Oil-specific demand shocks make variable countryspecific contributions across all countries. The contribution of other shocks in real exchange rate seems to be increasing during the first year in most of the sample oil-importing and oil-exporting countries. The shocks in real exchange rate at the first month have fairly no power in explaining industrial production variation in these countries. The explanatory power increases within all 
sample net oil-consuming and producing countries during the first six months and then varies across countries in no particular way.

\section{REFERENCES}

Alquist, R., and Kilian, L. (2010), ‘What Do We Learn From The Price Of Crude Oil Futures?’, Journal of Applied Econometrics, 25, 539-73.

Bohi, D.R. (1989), Energy Price Shocks and Macroeconomic Performance. Resources for the Future.

Burbidge, J. and Harrison, A. (1984), 'Testing For The Effects Of Oil-Price Rises Using Vector Autoregressions', International Economic Review, 25, 459-84.

Gisser, M., and Goodwin, T.H. (1986), 'Crude Oil and the Macroeconomy: Tests of Some Popular Notions: Note'. Journal of Money, Credit and Banking, 18, 95-103.

Hamilton, J.D. (1983), 'Oil and the Macroeconomy since World War II’, Journal of Political Economy, 91, 228-48.

Hamilton, J.D. (1996), 'This Is What Happened To The Oil Price-Macroeconomy Relationship'. Journal of Monetary Economics, 38, 215-20.

Hamilton, J.D. (2003), 'What Is An Oil Shock?’, Journal of Econometrics, 113, 363-98.

He, Y., Wang, S. and Lai, K.K. (2010), 'Global Economic Activity and Crude Oil Prices: A Cointegration Analysis’, Energy Economics, 32, 868-76.

Herrera, A.M., Lagalo, L.G. and Wada, T. (2011), 'Oil Price Shocks and Industrial Production: Is The Relationship Linear?’, Macroeconomic Dynamics, 15, 472-97.

Hooker, M.A. (1996), 'What Happened To The Oil Price-Macroeconomy Relationship?', Journal of Monetary Economics, 38, 195-213.

Jamil, M., Streissler, E.W. and Kunst, R.M. (2012), 'Exchange Rate Volatility and Its Impact on Industrial Production, Before and After the Introduction of Common Currency in Europe', International Journal of Economics and Financial Issues, 2, 85-109.

Jimenez-Rodriguez, R. (2008), 'The Impact Of Oil Price Shocks: Evidence from the Industries of Six OECD Countries', Energy Economics, 30, 3095-108.

Jimenez-Rodriguez, R. (2011), 'Macroeconomic Structure and Oil Price Shocks at the Industrial Level', International Economic Journal, 25, 173-89.

Jimenez-Rodriguez, R. and Sanchez, M. (2009), 'Oil Shocks and the Macro-Economy: A Comparison across High Oil Price Periods’, Applied Economics Letters, 16, 1633-38.

Jimenez-Rodriguez, R. and Sánchez, M. (2005), 'Oil Price Shocks and Real GDP Growth: Empirical Evidence for Some OECD Countries’, Applied Economics, 37, 201-28.

Jones, C.M. and Kaul, G. (1996), 'Oil and the Stock Markets’, Journal of Finance, 51, 463-91.

Jung, H. and Park, C. (2011), 'Stock Market Reaction to Oil Price Shocks: A Comparison between an OilExporting Economy and an Oil-Importing Economy', Journal of Economic Theory and Econometrics, 22, 1-29.

Kilian, L. (2008), 'A Comparison of the Effects of Exogenous Oil Supply Shocks On Output and Inflation in the G7 Countries', Journal of the European Economic Association, 6, 78-121.

Kilian, L. (2009), 'Not All Oil Price Shocks Are Alike: Disentangling Demand and Supply Shocks in the Crude Oil Market', American Economic Review, 99, 1053-69.

Kilian, L. and Park, C. (2009), 'The Impact of Oil Price Shocks On the US Stock Market', International Economic Review, 50, 1267-87.

Kyrtsou, C. and Labys, W.C. (2006), 'Evidence for Chaotic Dependence between US Inflation and Commodity Prices', Journal of Macroeconomics, 28, 256-66. 
Lardic, S. and Mignon, V. (2008), 'Oil Prices and Economic Activity: An Asymmetric Cointegration Approach’, Energy Economics, 30, 847-55.

Lee, K. and Ni, S. (2002), On The Dynamic Effects Of Oil Price Shocks: A Study Using Industry Level Data’, Journal of Monetary Economics, 49, 823-52.

Mackey, M.C. and Glass, L. (1977), 'Oscillation and Chaos in Physiological Control Systems’, Science, 197, 287-9.

Mork, K.A. (1989), 'Oil And The Macroeconomy When Prices Go Up And Down: An Extension Of Hamilton's Results', Journal of Political Economy, 97, 740-4.

Mork, K.A., Olsen, O. and Mysen, H.T. (1994), 'Macroeconomic Responses to Oil Price Increases and Decreases in Seven OECD Countries. Energy Journal, 15, 19-35.

Park, J. and Ratti, R.A. (2008), 'Oil Price Shocks and Stock Markets in the US and 13 European Countries. Energy Economics, 30, 2587-608.

Sotoudeh, M.A. and Worthington, A.C. (2014), 'Nonlinear Interest Rate Effects of Global Oil Price Changes: Comparison of Net Oil Consuming and Net Oil Producing Countries', Applied Economics Letters, 22, 693-9.

Wang, Y., Wu, C. and Yang, L. (2013), 'Oil Price Shocks and Stock Market Activities: Evidence from OilImporting and Oil-Exporting Countries’, Journal of Comparative Economics, 41, 1220-39. 
TABLE 1

Oil Consumption and Production Share of GDP in Sample Countries (1976-2011)

\begin{tabular}{|c|c|c|c|c|}
\hline Country & $\begin{array}{c}\text { Oil consumption } \\
\text { variation* }\end{array}$ & $\begin{array}{c}\text { Oil production } \\
\text { variation* }\end{array}$ & $\begin{array}{l}\text { Net oil consumption } \\
\text { share of GDP (\%)** }\end{array}$ & $\begin{array}{c}\text { Net oil production } \\
\text { share of GDP (\%)** }\end{array}$ \\
\hline Brazil & $984-2,629$ & $173-2,193$ & 1.89 & $\cdots$ \\
\hline Denmark & $176-326$ & $4-390$ & 0.80 & $\ldots$ \\
\hline Germany & 2,362-3,341 & NA & 2.10 & $\ldots$ \\
\hline Italy & 1,532-1,976 & 27-127 & 2.42 & $\ldots$ \\
\hline Netherlands & $610-1,122$ & NA & 3.09 & $\ldots$ \\
\hline Sweden & $305-564$ & NA & 2.21 & $\ldots$ \\
\hline USA & $15,235-20,802$ & $6,734-10,580$ & 1.66 & ... \\
\hline Canada & $1,540-2,298$ & $1,598-3,522$ & $\ldots$ & 0.72 \\
\hline Norway & $176-235$ & $279-3,418$ & $\ldots$ & 11.57 \\
\hline Mexico & $730-2,030$ & $894-3,766$ & $\ldots$ & 4.55 \\
\hline
\end{tabular}

Notes: * indicates thousand barrels daily. ** denotes the average annual index. Note that annual data used in this table but monthly data in estimations. Consequently, data period may differ. Source: IEA and World Bank websites.

TABLE 2

Parametric Nonlinear M-G Causality Test

\begin{tabular}{|c|c|c|c|c|c|c|c|}
\hline \multirow[b]{2}{*}{ Country } & \multicolumn{3}{|c|}{ OS shocks $-/ \rightarrow$ IP } & \multirow[b]{2}{*}{ Country } & \multicolumn{3}{|c|}{ AD shocks $-/ \rightarrow$ IP } \\
\hline & lag & power & test statistic & & lag & power & test statistic \\
\hline Brazil & 1 & 1 & 0.0580 & Brazil & 2 & 1 & 1.7226 \\
\hline Denmark & 3 & 1 & 0.3739 & Denmark & 5 & 1 & 1.0709 \\
\hline Germany & 3 & 1 & 0.2054 & Germany & 4 & 1 & 1.4068 \\
\hline Italy & 3 & 1 & 1.0613 & Italy & 3 & 1 & 2.1621 \\
\hline Netherlands & 2 & 1 & 0.9562 & Netherlands & 2 & 1 & 0.6241 \\
\hline Sweden & 1 & 1 & 0.3065 & Sweden & 1 & 1 & 0.3291 \\
\hline US & 1 & 1 & 0.3783 & US & 3 & 1 & 1.0546 \\
\hline Canada & 7 & 1 & 0.0108 & Canada & 3 & 1 & 0.8103 \\
\hline Norway & 1 & 1 & 0.5472 & Norway & 3 & 1 & $10.7032 * * *$ \\
\hline Mexico & 6 & 1 & $3.8841 * *$ & Mexico & 2 & 1 & 0.6295 \\
\hline \multirow[b]{2}{*}{ Country } & \multicolumn{3}{|c|}{ OD shocks $-/ \rightarrow$ IP } & & \multicolumn{3}{|c|}{ ER shocks $-/ \rightarrow$ IP } \\
\hline & lag & power & test statistic & Country & lag & power & test statistic \\
\hline Brazil & 1 & 1 & 2.7195 & Brazil & 1 & 1 & 1.2148 \\
\hline Denmark & 4 & 1 & 1.2757 & Denmark & 3 & 1 & 1.2619 \\
\hline Germany & 4 & 1 & 0.9665 & Germany & 3 & 1 & 0.1046 \\
\hline Italy & 8 & 1 & $13.4698 * * *$ & Italy & 3 & 1 & 1.3657 \\
\hline Netherlands & 3 & 1 & 0.3266 & Netherlands & 2 & 1 & 0.3918 \\
\hline Sweden & 1 & 1 & 0.5672 & Sweden & 2 & 1 & 0.5703 \\
\hline US & 1 & 1 & 0.2231 & US & 3 & 1 & 1.3986 \\
\hline Canada & 4 & 1 & 0.5016 & Canada & 3 & 1 & 0.4226 \\
\hline Norway & 1 & 1 & 1.5530 & Norway & 1 & 1 & 0.4730 \\
\hline Mexico & 1 & 1 & 0.1025 & Mexico & 1 & 1 & 2.4478 \\
\hline
\end{tabular}


TABLE 3

Correlation Coefficients of Impulse Responses to Oil Supply Shocks

\begin{tabular}{lllllllllll}
\hline & Brazil & Denmark & Germany & Italy & Netherlands & Sweden & US & Canada & Norway & Mexico \\
\hline Brazil & 1 & & & & & & & & & \\
Denmark & 0.66 & 1 & & & & & & & & \\
Germany & 0.83 & 0.77 & 1 & & & & & & & \\
Italy & 0.82 & 0.79 & 0.93 & 1 & & & & & & \\
Netherlands & 0.30 & -0.04 & 0.26 & 0.25 & 1 & & & & & \\
Sweden & 0.89 & 0.70 & 0.85 & 0.88 & 0.19 & 1 & & & & \\
US & 0.40 & 0.59 & 0.65 & 0.62 & 0.16 & 0.60 & 1 & & & \\
Canada & -0.54 & -0.16 & -0.28 & -0.29 & -0.01 & -0.35 & 0.47 & 1 & & \\
Norway & 0.79 & 0.47 & 0.63 & 0.63 & 0.13 & 0.75 & 0.18 & -0.63 & 1 & \\
Mexico & 0.14 & 0.28 & 0.23 & 0.23 & -0.03 & 0.37 & 0.76 & 0.58 & 0.01 & 1 \\
\hline
\end{tabular}

TABLE 4

Correlation Coefficients of Impulse Responses to Aggregate Demand Shocks

\begin{tabular}{lllllllllll}
\hline & Brazil & Denmark & Germany & Italy & Netherlands & Sweden & US & Canada & Norway & Mexico \\
\hline Brazil & 1 & & & & & & & & & \\
Denmark & -0.30 & 1 & & & & & & & & \\
Germany & 0.78 & 0.13 & 1 & & & & & & & \\
Italy & 0.34 & 0.61 & 0.77 & 1 & & & & & & \\
Netherlands & 0.25 & 0.08 & 0.49 & 0.49 & 1 & & & & & \\
Sweden & 0.88 & -0.20 & 0.82 & 0.47 & 0.23 & 1 & & & & \\
US & -0.83 & 0.61 & -0.43 & 0.14 & 0.03 & -0.67 & 1 & & & \\
Canada & -0.85 & 0.55 & -0.48 & 0.07 & 0.01 & -0.70 & 0.98 & 1 & & \\
Norway & -0.26 & 0.30 & 0.11 & 0.30 & 0.41 & -0.06 & 0.47 & 0.45 & 1 & \\
Mexico & -0.37 & 0.76 & -0.15 & 0.36 & 0.10 & -0.38 & 0.60 & 0.56 & 0.06 & 1 \\
\hline
\end{tabular}

TABLE 5

Correlation Coefficients of Impulse Responses to Other Shocks in Oil Price

\begin{tabular}{lllllllllll}
\hline & Brazil & Denmark & Germany & Italy & Netherlands & Sweden & US & Canada & Norway & Mexico \\
\hline Brazil & 1 & & & & & & & & & \\
Denmark & 0.76 & 1 & & & & & & & & \\
Germany & 0.82 & 0.68 & 1 & & & & & & & \\
Italy & 0.86 & 0.86 & 0.90 & 1 & & & & & & \\
Netherlands & 0.85 & 0.69 & 0.87 & 0.91 & 1 & & & & & \\
Sweden & 0.82 & 0.81 & 0.91 & 0.96 & 0.86 & 1 & & & & \\
US & 0.86 & 0.87 & 0.85 & 0.98 & 0.87 & 0.96 & 1 & & & \\
Canada & 0.82 & 0.82 & 0.90 & 0.94 & 0.85 & 0.97 & 0.95 & 1 & & \\
Norway & 0.73 & 0.75 & 0.64 & 0.85 & 0.75 & 0.75 & 0.82 & 0.69 & 1 & \\
Mexico & 0.76 & 0.82 & 0.71 & 0.85 & 0.72 & 0.74 & 0.84 & 0.71 & 0.74 & 1 \\
\hline
\end{tabular}

TABLE 6

Correlation Coefficients Of Impulse-Responses To Other Shocks In Real Exchange Rate

\begin{tabular}{|c|c|c|c|c|c|c|c|c|c|c|}
\hline & Brazil & Denmark & Germany & Italy & Netherlands & Sweden & US & Canada & Norway & Mexico \\
\hline Brazil & 1 & & & & & & & & & \\
\hline Denmark & 0.46 & 1 & & & & & & & & \\
\hline Germany & 0.89 & 0.68 & 1 & & & & & & & \\
\hline Italy & 0.80 & 0.79 & 0.94 & 1 & & & & & & \\
\hline Netherlands & 0.54 & 0.02 & 0.53 & 0.42 & 1 & & & & & \\
\hline Sweden & 0.93 & 0.48 & 0.85 & 0.81 & 0.42 & 1 & & & & \\
\hline US & 0.81 & 0.77 & 0.93 & 0.96 & 0.38 & 0.85 & 1 & & & \\
\hline Canada & 0.73 & 0.18 & 0.49 & 0.49 & 0.26 & 0.79 & 0.50 & 1 & & \\
\hline Norway & -0.71 & -0.50 & -0.65 & -0.62 & -0.24 & -0.65 & -0.69 & -0.47 & 1 & \\
\hline Mexico & 0.90 & 0.39 & 0.81 & 0.75 & 0.45 & 0.90 & 0.74 & 0.79 & -0.57 & 1 \\
\hline
\end{tabular}


Net oil-consuming countries
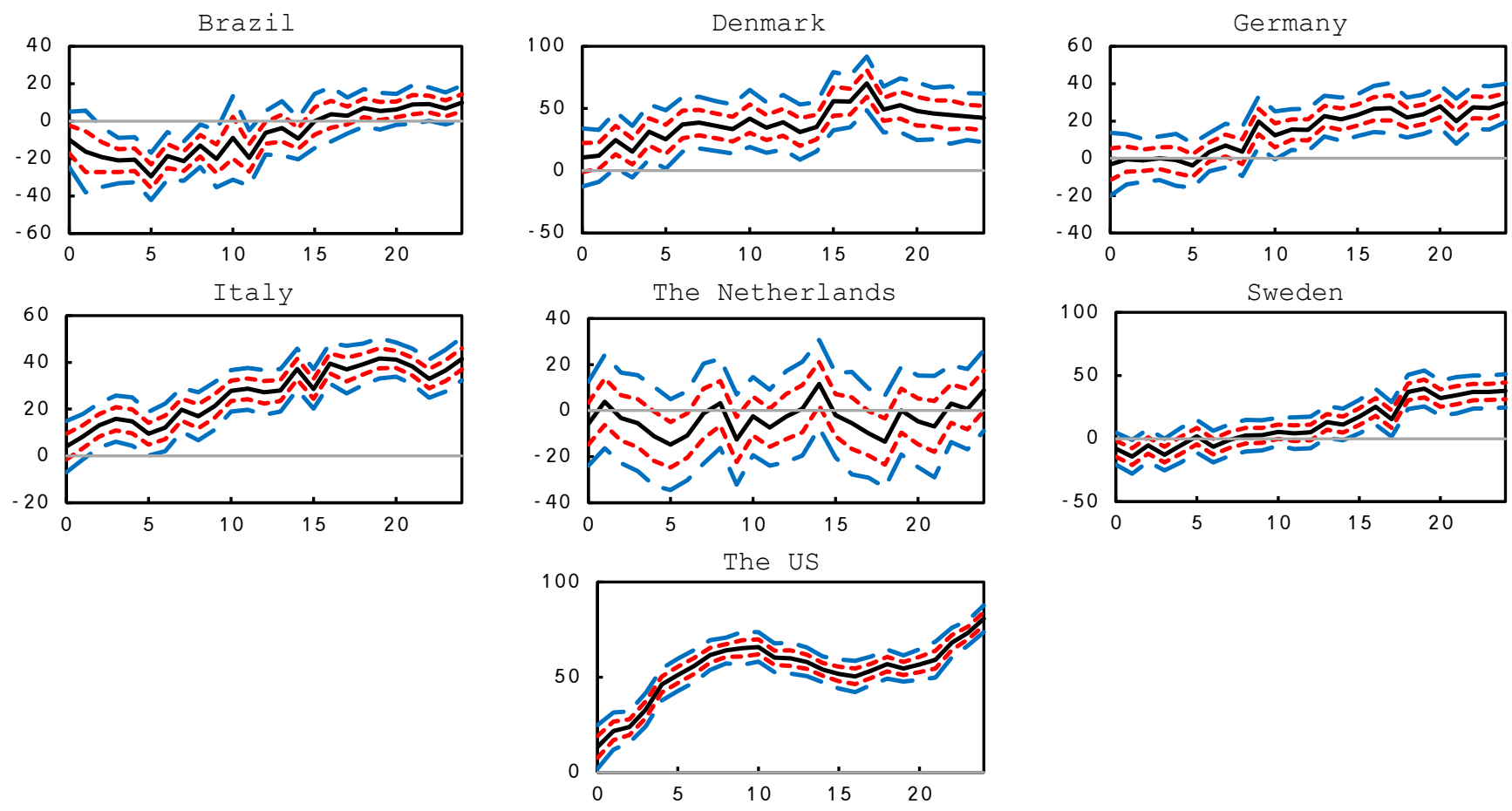

Net oil-producing countries
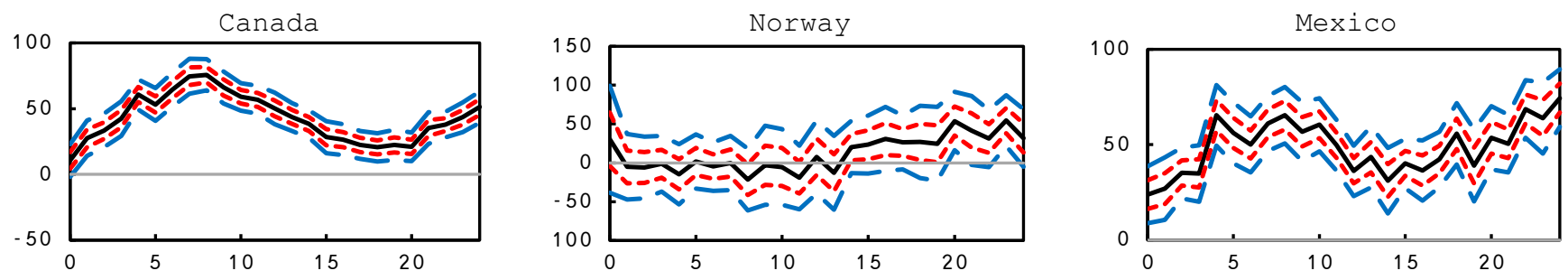

Fig. 1. Industrial production responses to oil supply shocks. Horizontal axis indicates time (in months) and vertical axis indicates variation (in percent). 
Net oil-consuming countries
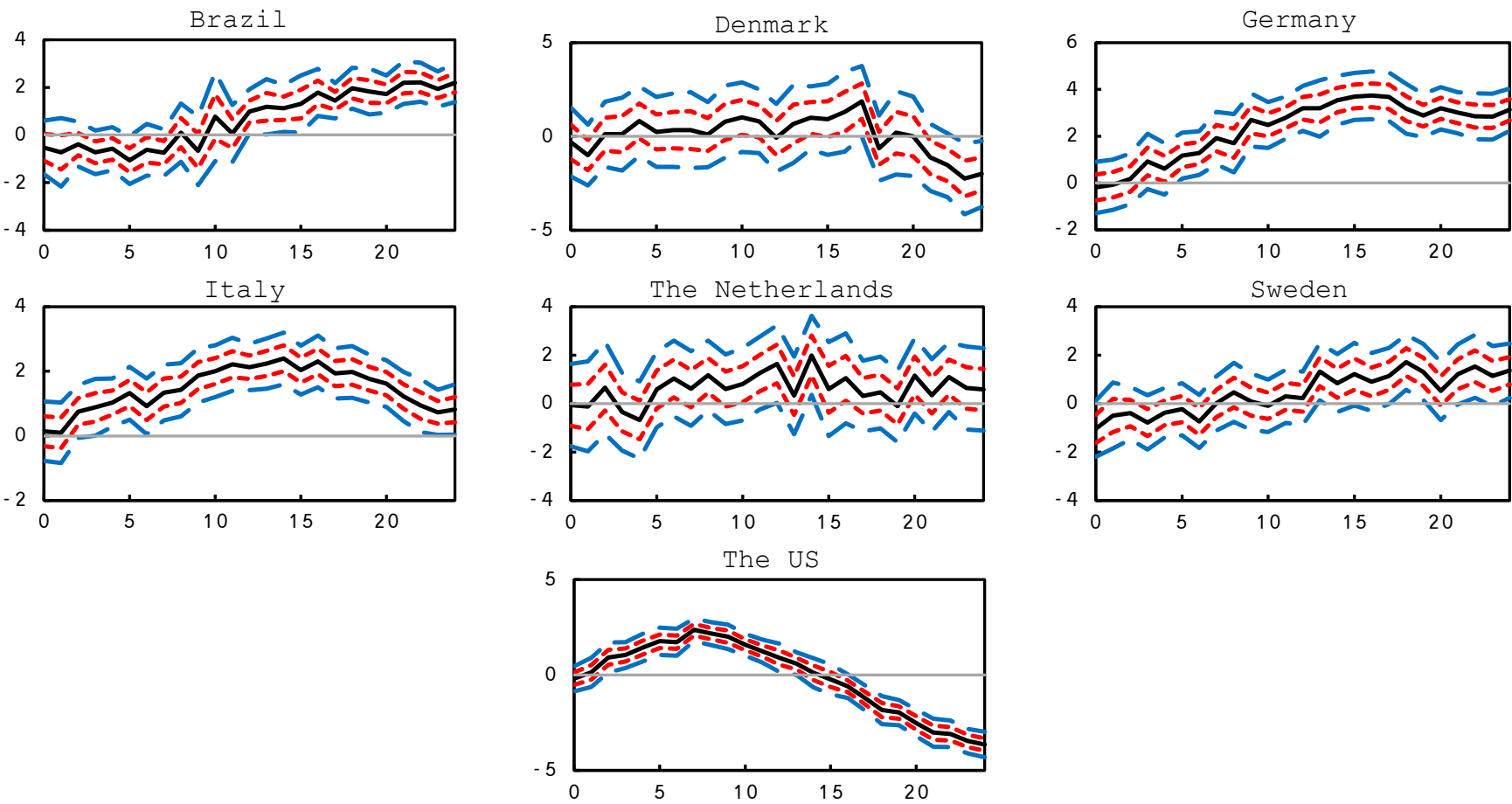

Net oil-producing countries
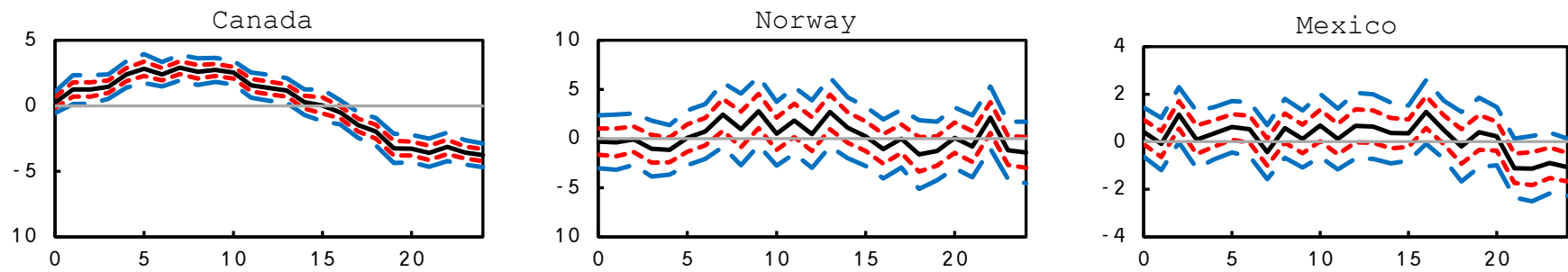

Fig. 2. Industrial production responses to aggregate demand shocks. Horizontal axis indicates time (in months) and vertical axis indicates variation (in percent). 
Net oil-consuming countries
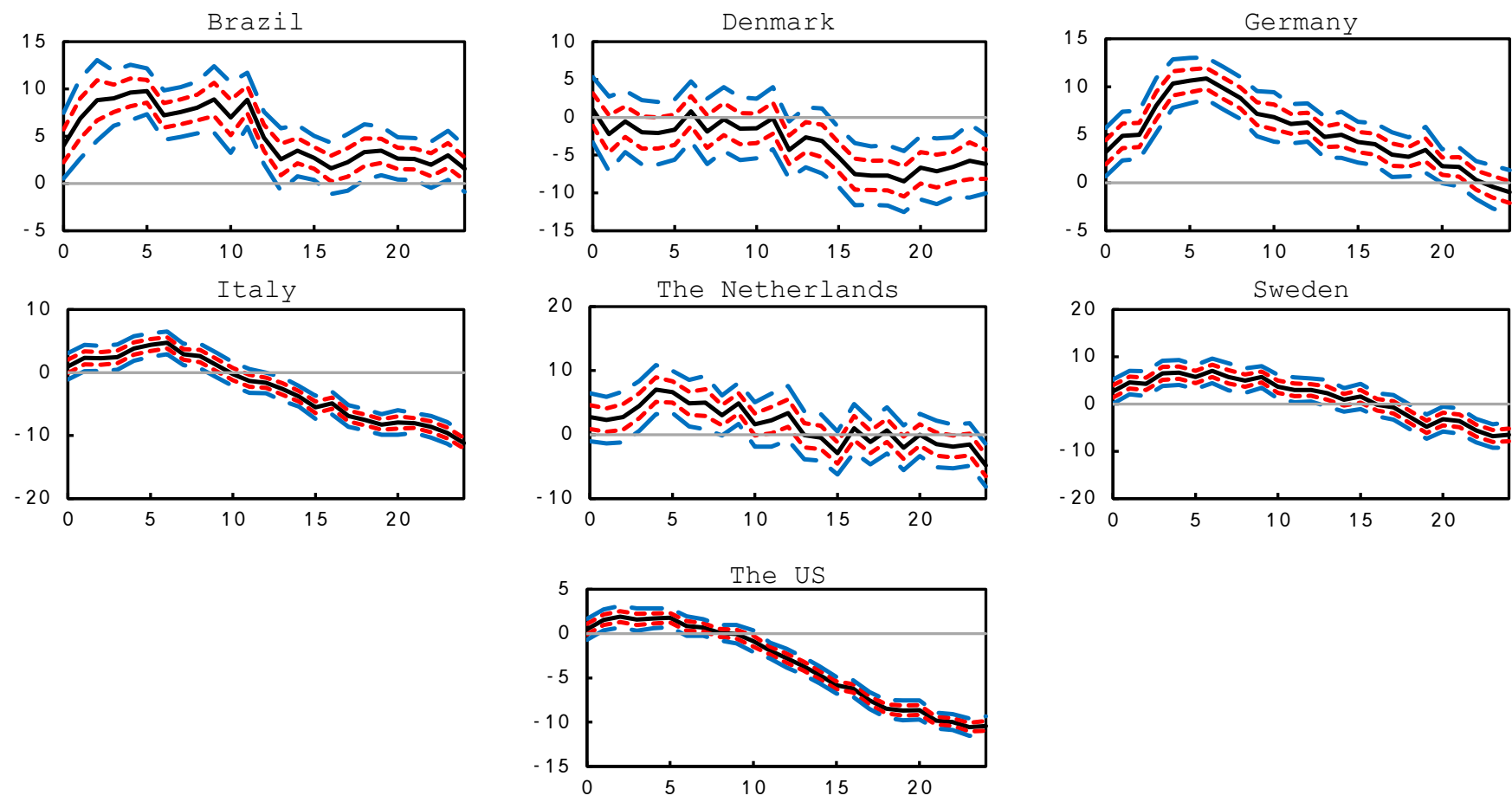

Net oil-producing countries
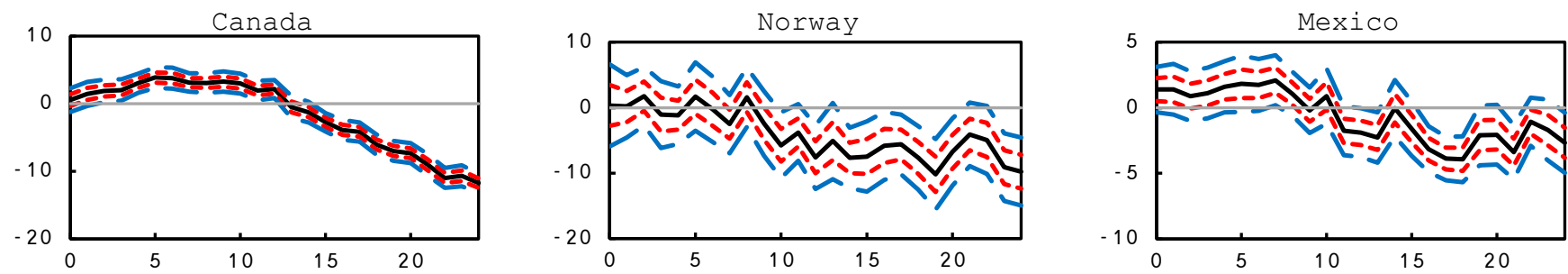

Fig. 3. Industrial production responses to other oil price shocks. Horizontal axis indicates time (in months) and vertical axis indicates variation (in percent). 
Net oil-consuming countries
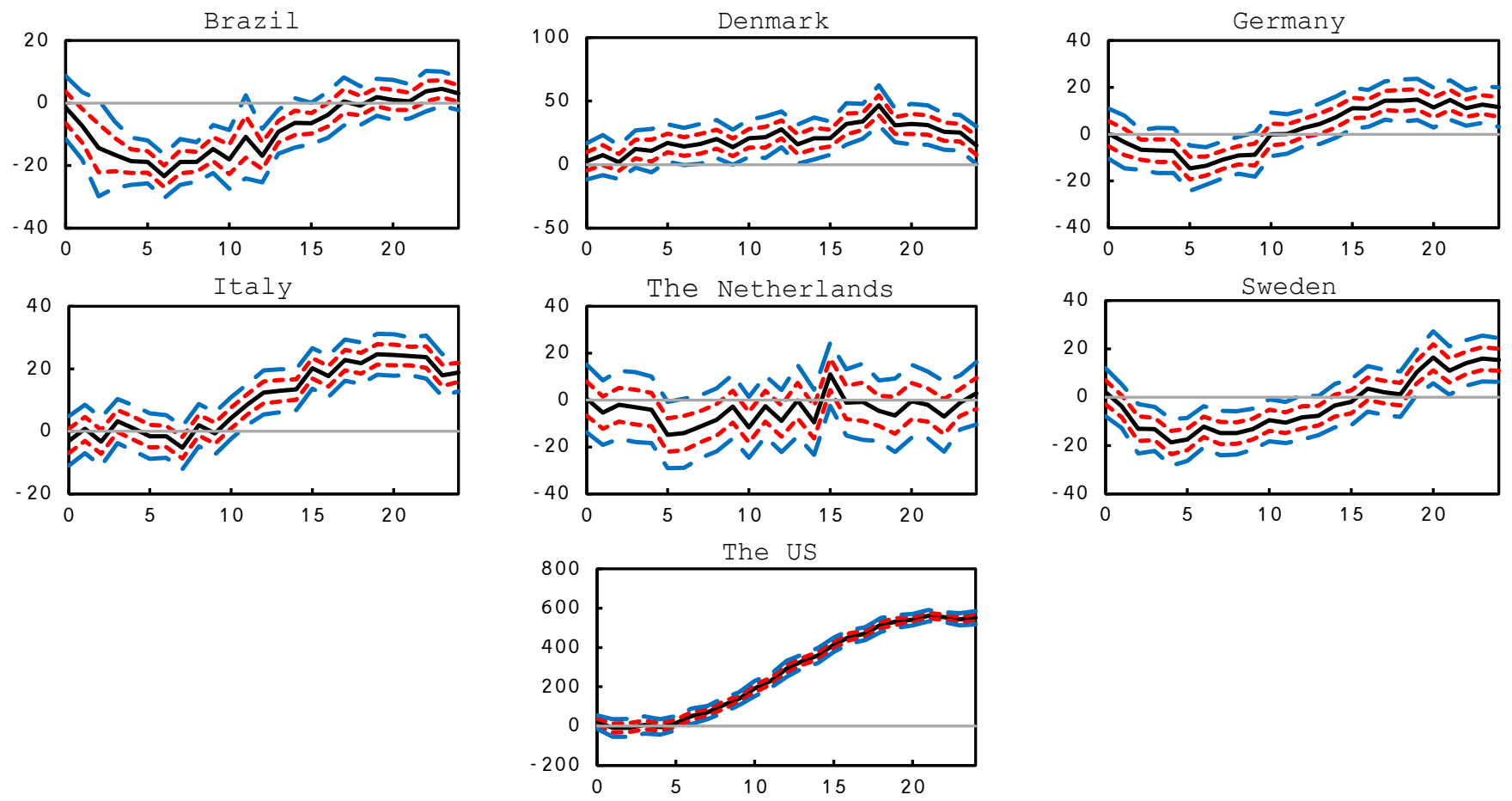

Net oil-producing countries
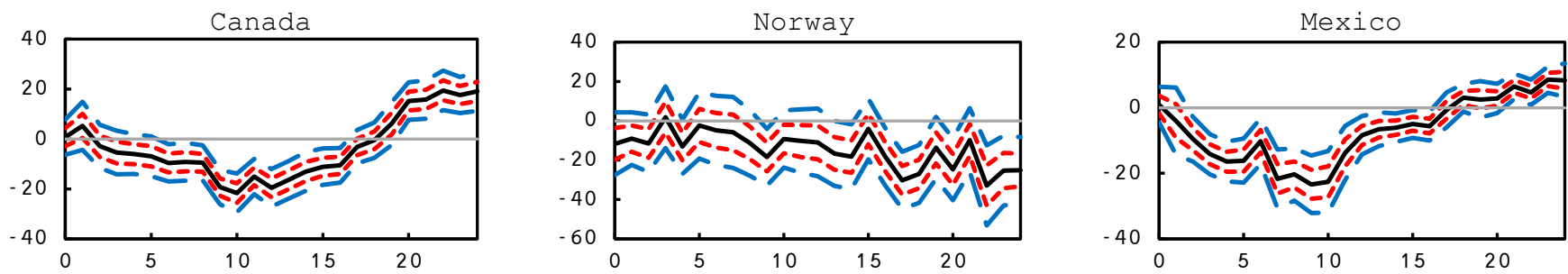

Fig. 4. Industrial production responses to non-oil shocks in real exchange rate. Horizontal axis indicates time (in months) and vertical axis indicates variation (in percent). 
Net oil-consuming countries
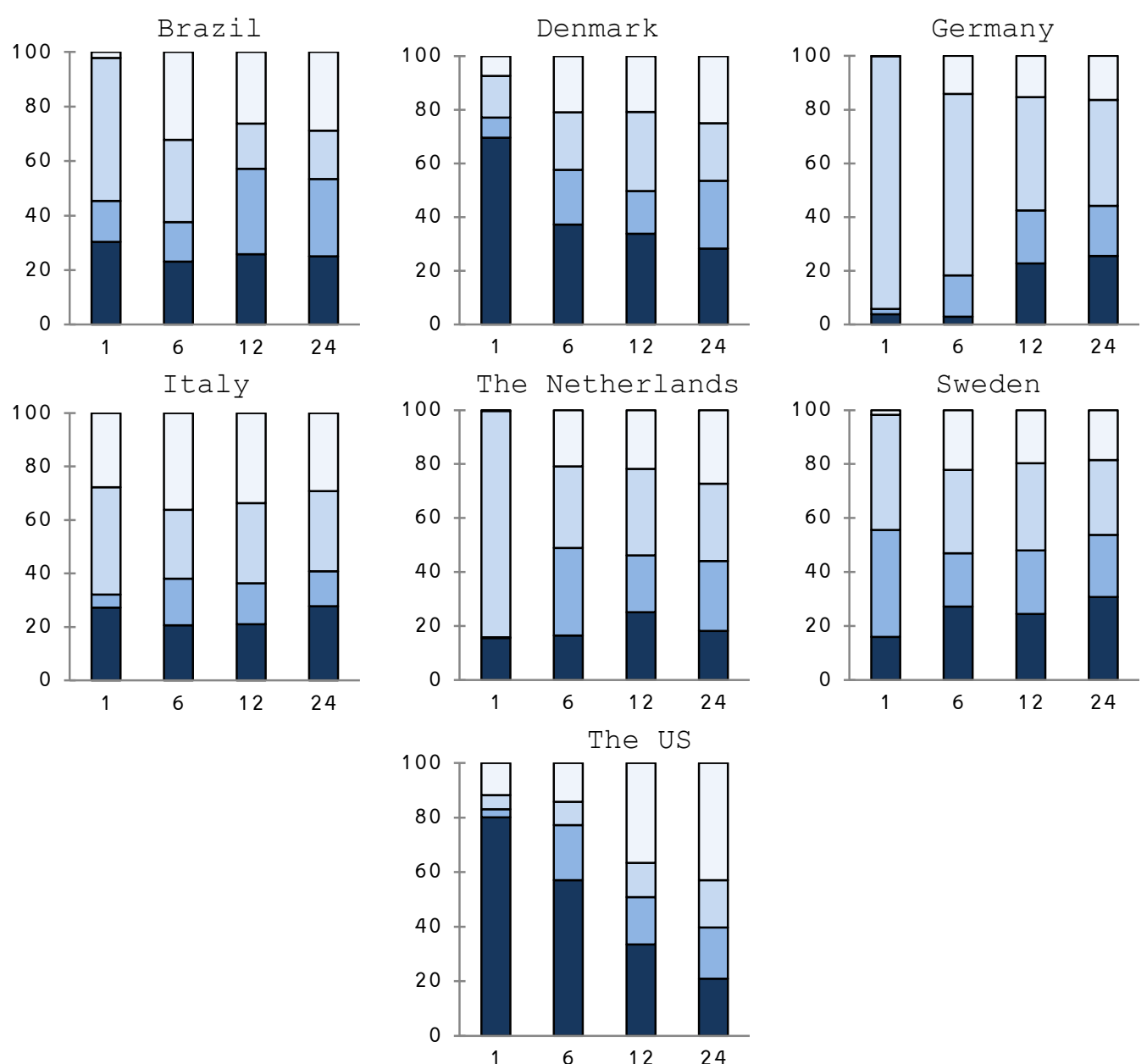

Oil supply shocks

$\square$ Aggregate demand shocks

$\sqsubset$ Other oil price shocks

$\varpi$ Other real exchange rate shocks

Fig 5. Forecast error variance decomposition of economic activity responses to global oil price shocks. Horizontal axis indicates time horizon for 1, 6, 12 and 24 months and the vertical axis indicates cumulative percentage. 
Net oil-producing countries
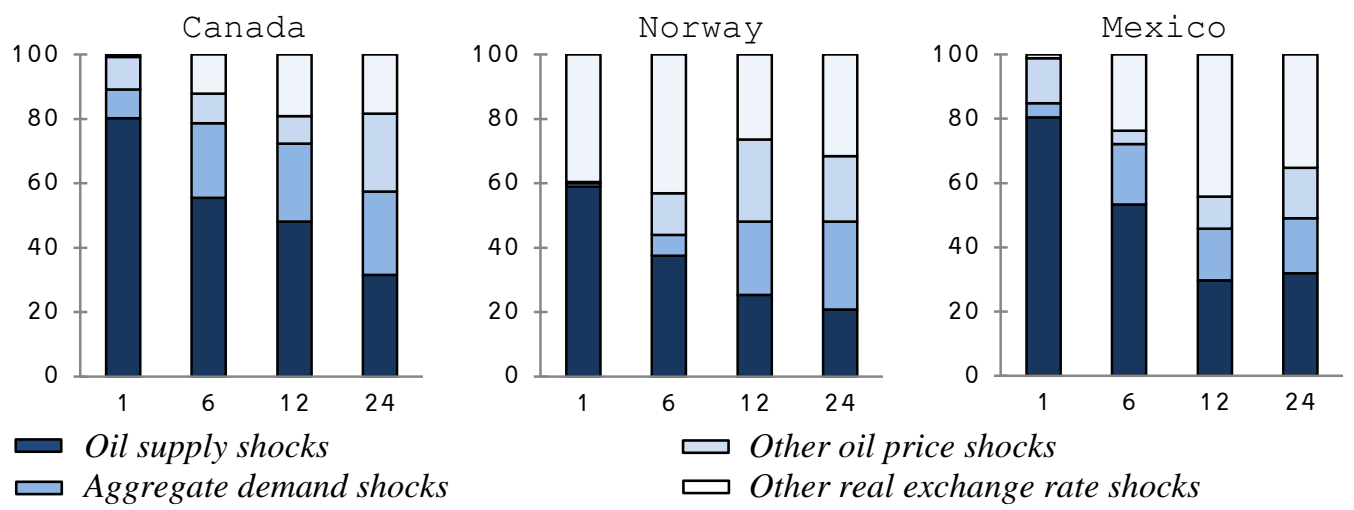

$\sqsubset$ Other oil price shocks

$\square$ Other real exchange rate shocks

Fig 6. Forecast error variance decomposition of economic activity responses to global oil price shocks. Horizontal axis indicates time horizon for 1, 6, 12 and 24 months and the vertical axis indicates cumulative percentage. 